\title{
Derechos humanos y estrategias de la oposición bajo la dictadura militar argentina
}

Débora Carina D'Antonio

A curta presença da Comissão Interamericana de Direitos Humanos da Organização dos Estados Americanos foi fundamental para o enfraquecimento da ditadura militar na Argentina. Antes de sua atuação, os movimentos populares eram controlados por meio de atos violentos e terroristas. O CIDH atuou como uma caixa de ressonância da resistência argentina.

Palabras clave: Ditadura, Oposição, Resistências, Direitos Humanos-CIDH.
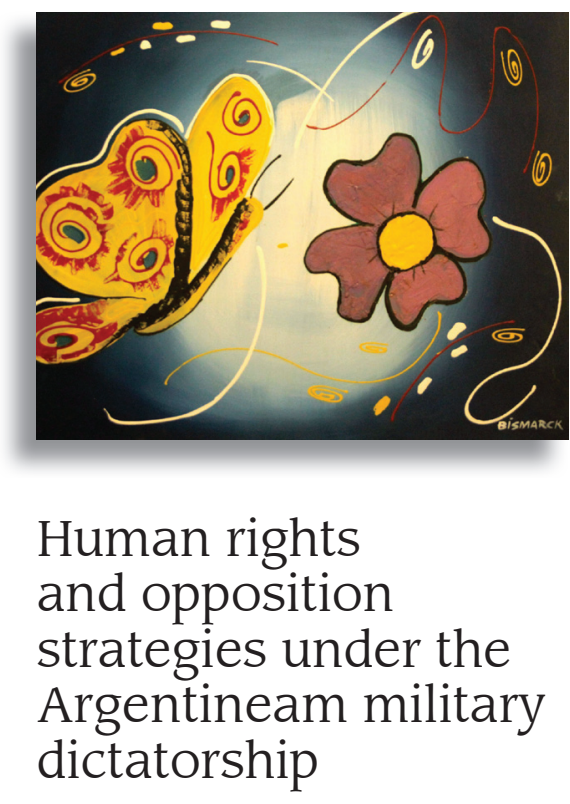

The brief presence of the Commission on Human Rights of the Organization of American States was instrumental in weakening the military dictatorship in Argentina. Before its performance, the popular movements were controlled by means of violent and terrorist acts. The IACHR has acted as a sounding board of the Argentine resistance.

\section{Débora Carina D'Antonio:}

Doutora em História e pesquisadora do Instituto Interdisciplinário de Estudos de Gênero da Universidade de Buenos Aires.

Key words: Dictatorship, Opposition, Resistance, Human Rights-IACHR. 


\section{INTRODUCIÓN}

Por creer que el derecho a la seguridad es un derecho humano que el Estado debe proteger, los argentinos recibimos hoy la visita de la CIDH. Esto es lo malo. Que están aquí porque somos derechos y humanos (Mariano Grondona en El Cronista Comercial, 12 de septiembre de 1979). ${ }^{1}$

En los tres primeros años de la última dictadura militar argentina (1976-1983) parecía que el dominio sobre la sociedad civil era ciertamente absoluto, apuntalado, inicialmente, por el consenso que obtuvo el golpe de Estado entre numerosos sectores y, ciertamente, por las masivas persecuciones a la militancia popular. Sin embargo, entre otros factores, desde la llegada de la Comisión Interamericana de Derechos Humanos $(\mathrm{CIDH})^{2}$ se abrió un proceso de erosión de determinados atributos del poder militar, fundamentalmente aquellos vinculados con el ejercicio terrorista de la violencia, lo cual posibilitó una resistencia cada vez más pública de distintos actores sociales, que denunciaron la existencia de campos clandestinos de detención (CCD), desapariciones forzadas de personas y otras vejaciones practicadas en las cárceles contra los presos y presas políticos.

Aunque la $\mathrm{CIDH}$ solo estuvo presente en el país por el término de dos semanas, del 6 al 20 de septiembre de 1979, la Comisión recibió más de cinco mil denuncias efectuadas centralmente por presos políticos, familiares y organismos de derechos humanos, tales como el Centro de Estudios Legales y Sociales (CELS), la Asamblea Permanente por los Derechos Humanos (APDH) o la Liga Argentina por los Derechos del Hombre (LADH), entre otros.

Tanto las "recomendaciones preliminares", un escrito de carácter urgente que los miembros de la $\mathrm{CIDH}$ entregaron a la Junta Militar al finalizar su visita, como el informe definitivo que sería enviado a la OEA, tan solo unos meses después, en abril de 1980, fueron ostensiblemente condenatorios de las prácticas represivas del

\footnotetext{
1 Mariano Grondona es un periodista, ensayista y profesor universitario que ha apoyado activamente y en distintas oportunidades las intervenciones de las Fuerzas Armadas en la vida política argentina.

2 Desde un punto de vista constitutivo la CIDH es un órgano principal, autónomo y consultivo de la Organización de los Estados Americanos (OEA) y fue creado en 1959 para promover la observancia y la defensa de los derechos humanos entre los países miembros. Actúa en representación y está integrado por siete personas de reconocida trayectoria en la temática, quienes son elegidos por su mérito personal y no representan a ningún país en particular. La CIDH conforma junto a la Corte Interamericana de Derechos Humanos el sistema interamericano de protección a los derechos humanos en todo el continente.
} 
régimen. El gobierno ante esta fuerte crítica debió articular rápidamente un "contrainforme" para defenderse de lo que consideraba un ataque, y contribuyó, con su respuesta, al aglutinamiento de una corriente política y social en su favor.

El terrorismo de Estado se erigió entre lo visible y lo oculto de sus prácticas represivas y criminales, una dialéctica que tuvo por finalidad no afectar de modo directo la legitimidad del régimen militar. En el particular contexto de la llegada de la Comisión, esta ecuación se modificó, tornándose cada vez más visible lo que hasta allí se había intentado ocultar. En efecto, hasta ese momento, el gobierno había logrado imponer su agenda respecto de cómo se articulaba lo que se quería mostrar y lo que se ocultaba respecto de su actividad represiva.

La visibilización de los factores más violentos desplegados por las fuerzas armadas, potenció, a la vez, la prédica y la escucha de los familiares, que hasta ese momento habían sido desestimados, maltratados o en el caso de las Madres de Plaza de Mayo incluso acusadas de locas, ${ }^{3}$ y también algunas otras secuestradas y posteriormente asesinadas. ${ }^{4}$ Las desapariciones, encarcelamientos prolongados, torturas y asesinatos que hasta no hacía mucho tiempo se habían manejado de forma soterrada y discrecional adquirieron, a partir de ese momento, un carácter cada vez más visible y público. A esto se le sumó una disputa entre las distintas facciones militares en torno a cómo debía tratarse oficialmente la cuestión de la lucha antisubversiva y sus secuelas, lo que ahondó aún más las grietas internas que ya se habían abierto en las filas castrenses. La visita entonces provocó malestares, reacomodamientos y reagrupamientos en el gobierno, y en sectores aliados y adversos a él.

Interpretamos entonces que la llegada de la CIDH debe ser entendida no como la agencia de un organismo internacional que logró torcer el rumbo del régimen militar, sino como un hecho clave de la historia reciente argentina, que permitió sintetizar el reacomodamiento político que se estaba gestando tanto a nivel local como internacional con respecto al tema de los derechos humanos. No se trata, por lo tanto, de una interpretación causal del rol de este arribo, sino

\footnotetext{
3 Distintos miembros del gobierno se referían a las Madres de Plaza de Mayo como "locas" por sostener públicamente la denuncia de desaparición de sus hijos e hijas. Esta calificación tomó relieve internacional (Ver BOUSQUET, 1980).

4 En diciembre de 1977 secuestraron y desaparecieron, junto a otros familiares, a las monjas francesas Léonie Duquet y Alice Domon, y a Esther Ballestrino Careaga, Mary Bianco y Azucena Villaflor de Vincenti, Madres de la Plaza de Mayo.
} 
de un análisis del proceso social y político expresado en la decisión de la OEA de enviar a la Comisión y de las distintas intervenciones de las fuerzas sociales que apostaron a aprovechar, en su favor políticamente, este evento. La mera actuación del organismo, sin estas presencias que lo interpelaron, no hubiera generado por entonces, mayores cambios en el accionar represivo.

\section{LAS CONTROVERSIAS ANTE LA LLEGADA DE LA CIDH}

El arribo de la CIDH a la Argentina se iba a concretar en los primeros meses del año 1979 tras la acumulación de una serie de denuncias realizadas ante la prensa extranjera durante el Mundial de fútbol, por parte de los/as familiares de personas apresadas y desaparecidas. ${ }^{5}$ También contribuyó con este mismo fin, el trabajo paciente y sistemático de los/as exiliados/as y expulsados/as por distintos gobiernos dictatoriales del Cono Sur hacia Europa, a los Estados Unidos o a algunos países de Latinoamérica como México o Venezuela, entre otros. Sin embargo, la visita se postergó por más de medio año, hasta después de realizada la Asamblea Extraordinaria de la OEA en la que se renovarían a los integrantes de la Comisión. Esta demora le permitió al gobierno "simular" una invitación, y reconocer por medio de su ministro del Interior, Albano Harguindeguy, ${ }^{6}$ que ofrecerían a los miembros de la misma, facilidades y garantías para que pudiesen cumplir con los objetivos previstos. ${ }^{7}$ Para el gobierno resultaba fundamental presentar la visita como una cuestión de Estado impulsada por su propia administración, la cual no tenía nada que ocultar. Este era el mejor remedio para invisibilizar la voz de los activistas en el exilio y la de los familiares en el país, que en caso de comprobarse las denuncias, podrían llegar a vulnerar la estabilidad del poder militar. Harguindeguy afirmó,

5 Al finalizar el "Mundial del fútbol" en junio de 1978, y por las numerosas presiones internacionales, el Ejército comenzó a predicar que el período de "excepcionalidad" o de lucha contra la subversión había terminado. Esta intervención política tuvo por objetivo desestimar ante los veedores internacionales las implicancias de la "guerra sucia". En este marco el general Harguindeguy, comenzó a arengar a su tropa policial para que retornase a sus funciones históricas dejando a un lado todo posible "desborde" (LA NACIÓN, 4 de mayo de 1978).

6 Harguindeguy fue un teniente general del Ejército que ocupó el cargo de ministro del Interior entre los años 1976 y 1981. Estuvo dentro de sus funciones confeccionar y publicar listas de detenidos y desaparecidos, las cuales fueron calificadas por los familiares como completamente "ineficaces" o directamente "falaces".

7 El secretario ejecutivo de la CIDH por aquel entonces, Edmundo Vargas Carreño, afirmó en una entrevista ofrecida a la prensa en el aniversario número treinta de la visita, que la Comisión nunca recibió por parte del gobierno militar ningún estímulo para el desarrollo de sus tareas en el país (PÁGINA 12, 15 de septiembre de 2009). 
de este modo, ante el hecho consumado de la venida de la Comisión que esta:

tendrá amplia libertad de acción porque así lo ha considerado prudente el gobierno, ya que nos interesa que después de la lucha que hemos sufrido, la OEA vea cuál es nuestra realidad presente $[\ldots]^{8}$

Desde esta lógica, la CIDH parecía venir a corroborar la "reconstrucción política" que la dictadura se había propuesto alcanzar después de su lucha contra el ataque sufrido por el "comunismo internacional". Un relato que procuraba borrar las denuncias y los reclamos llevados adelante por familiares ante organismos judiciales, la jerarquía eclesiástica u oficinas del Ministerio del Interior u otras delegaciones estatales.

Harguindeguy patentizaba una omnipotencia que sustentaban también otros integrantes del gobierno, los cuales creían que los miembros de la CIDH solo se concentrarían en lo que se suponía que "debían ver". 9 Para los jefes militares en el poder, formados al calor de la Guerra Fría, resultaba insospechado que un organismo de la OEA, impulsado por los Estados Unidos, pudiese condenar la "justa" lucha contra la "subversión". Máxime cuando la OEA había funcionado durante la segunda mitad del siglo XX como una oficina de la política exterior norteamericana, profundamente anticomunista, políticamente de derecha y fuertemente anticubana. Tampoco era predecible para el régimen militar, una opinión pública mundial masivamente proclive a la institucionalización del discurso de los derechos humanos. El gobierno deseaba apostar a una reubicación de la Argentina en el plano internacional con el afán de captar futuros inversores, dejando atrás el aislamiento y la imagen negativa que se había erigido durante los breves años de gestión.

El ocaso de las dictaduras militares latinoamericanas y el desmoronamiento de las experiencias del "socialismo real" en los años ochenta y noventa fueron transformando poco a poco el discurso de los derechos humanos en una perspectiva homologada por la mayor parte de los Estados del mundo. Si hoy en día se nos presenta como "natural" la defensa de estos derechos, en los años setenta, sin embargo, no formaba todavía parte de un imaginario internacional tan usual ni tan compartido.

8 "La CIDH llegará al país junto a la próxima primavera", en Convicción, 20 de abril de 1979.

9 La CIDH contaba, además, con la calificación que había realizado Amnesty International tres años antes, en 1976, cuando tras su visita a la Argentina, publicó en su informe anual, una primera y amplia lista de nombres de personas desaparecidas. Ver Causa n. ${ }^{\circ} 13 / 84$, capítulo n. ${ }^{\circ}$ XIX, originariamente instruida por el Consejo Supremo de las Fuerzas Armadas en cumplimiento del decreto 158/83 del Poder Ejecutivo Nacional" y posteriormente conocida como actas judiciales contra las Juntas Militares. www.derechos.org/nizkor/arg/causa13/ 
Por el contrario, prevalecían miradas contendientes de los sectores de izquierda, por un lado, y de los defensores de la Doctrina de la Seguridad Nacional ${ }^{10}$ por el otro.

En los Estados Unidos el predominio de la ideología de la Guerra Fría en los años sesenta y primeros setenta era absolutamente dominante. Se trataba de una potencia que por décadas había encabezado una cruzada anticomunista con políticas persecutorias ofensivas y enérgicas en su propio territorio, y articuladora, con el mismo fin, de alianzas políticas y militares con los regímenes más represivos de Latinoamérica. Incluso, líderes demócratas como John F. Kennedy (1961-1963) apoyaron a las dictaduras latinoamericanas o caribeñas, justificándose en que era necesario erradicar potenciales experiencias de tipo cubanas o soviéticas.

Desde el punto de vista de los militares argentinos parecía razonable interpretar las acciones de James Carter (1977-1981), quien dio un giro en la política exterior norteamericana en torno a la defensa de los derechos humanos, como una mera retórica o como un discurso que no iba a tener mayores consecuencias en el plano internacional.

Al mismo tiempo, los "recomendaciones" que proporcionó en octubre de 1976 el canciller norteamericano, Henry Kissinger, al canciller del gobierno militar, César Guzzetti, no permitían tampoco prever el cambio de actitud que desplegarían los norteamericanos, tan solo unos años más tarde. En efecto, Kissinger no solo no condenó el accionar militar del gobierno argentino, sino que, por el contrario, lo instó a la rapidez, efectividad e invisibilidad. ${ }^{11}$ La solicitud de celeridad y discreción en la "lucha antisubversiva", no fue evaluada correctamente ni mucho menos a tiempo por la Junta Militar.

10 Ver distintos enfoques de la doctrina en Garretón (1978), Tapia Valdés (1980, 1988), García (1991), Leal Buitrago (2002), Robin (2005) y Smith (2008).

11 Reproducimos in extenso la comunicación que el canciller Henry Kissinger desarrolló con César Guzzetti, ya que en ella se pone de claro manifiesto, que no hubo intención ni ánimo de evitar ni de atemperar ninguna masacre en la Argentina. Dice Kissinger: "Mire, nuestra actitud básica es que queremos que ustedes tengan éxito. Yo tengo un punto de vista pasado de moda que es apoyar a los amigos. Lo que no se entiende en los EEUU es que ustedes están en una guerra civil. Nosotros leemos sobre los problemas con los derechos humanos, pero no vemos el contexto. Cuanto más rápido ustedes tengan éxito, mejor. El problema de los derechos humanos está creciendo (en EEUU). Su embajador puede informarlo. Queremos una situación estable. No queremos causarles dificultades innecesarias. Si ustedes pueden terminar antes de que el Congreso reanude sus sesiones, mejor. Todas las libertades que restituyan ayudaría". Ver los documentos en el sitio del National Security Archive http://foia.state.gov/ SearchColls/Search.asp, específicamente la serie de diez documentos de U.S. State Department, Argentina Declassification Project (1975-1984), August 20, 2002. 
Mientras la opinión pública mundial se volcaba entonces a un rechazo u oposición a las dictaduras del Cono Sur, el gobierno argentino seguía pensando la cuestión de la "subversión" desde una perspectiva localista y con la mentalidad de la Doctrina de la Seguridad Nacional, la cual ya no solo no tenía la capacidad hegemónica de antaño, sino que además comenzaba a ser percibida por distintos sectores como ilegítima.

La subestimación del rol que pudiera tener la CIDH y la manipulación de su visita descansó, además, en la caracterización política que el régimen militar hizo sobre algunos de sus miembros, quienes, por otro lado, no habían visto tan mal, unos pocos años antes, aquello de ponerle freno a la violencia guerrillera a través de una enérgica intervención estatal. ${ }^{12}$ No obstante existían indicios que podrían haberle permitido a la Junta conjeturar respecto de cómo podrían ubicarse los miembros de la Comisión cuando arribaran a la Argentina. Un ejemplo de ello es un informe elaborado por la Dirección de Inteligencia de la Policía de la Provincia de Buenos Aires (DIPBA) ${ }^{13}$ en donde se alerta que la visita de la CIDH a territorio nicaragüense en octubre de 1978, tan sólo unos meses antes, tuvo por finalidad investigar las violaciones a los derechos humanos que sucedieron durante la dictadura de Anastasio Somoza, otorgándole un valor decisivo a las denuncias de los testimoniantes. ${ }^{14}$ Paradójicamente, mientras se sucedía el arribo de la CIDH a la Argentina al año siguiente, el gobierno enviaba "cuadros" del Ejército a instruir a los "contras nicaragüenses", a la par que los norteamericanos representaban a estos sectores como los freedom fighters.

Entre las armas (Ejército, Armada y Aeronáutica) existía un fuerte acuerdo alrededor de la negativa a rendirle cuentas a nadie respecto de

12 Edmundo Vargas Carreño aclaró, en relación con este punto, las diferencias que existían entre los integrantes de la CIDH: "algunos miembros de la Comisión, una minoría, si bien sabían que había graves violaciones a los derechos humanos, compartían el punto de vista sobre el "estado de subversión". Pero no hay mal que por bien no venga: el gobierno creyó que esa gente representaba a la Comisión. Sin embargo, después de una discusión inicial, el tema quedó saldado." "Hubo desprecio, gritos y provocaciones", en Página 12, 15 de septiembre de 2009.

13 La DIPBA fue una central de inteligencia dependiente de la Policía de la Provincia de Buenos Aires, creada en el año 1956.

14 Ver Comisión Provincial por la Memoria, archivo DIPBA, Mesa Ds, Carpeta Varios, Legajo 14.413. Asunto: CIDH. Actividades desarrolladas en Nicaragua y varios de la LADH en Argentina. Memorando estrictamente confidencial y secreto, producido por el Sr. Jefe Delegación Capital para información de Sr. Director Gral. Inteligencia; Bs. As. 18 de mayo de 1979. 
la "lucha antisubversiva". Lo que no significa que no florecieran diferencias en torno a cómo debía encararse este tema en la agenda pública. Siguiendo en estos lineamientos a Paula Canelo, sabemos que se desarrollaron dos perspectivas en las fuerzas armadas. Por un lado existía el sector de los "clausuristas", que veían necesario "blanquear" la cuestión represiva, al menos comenzando a hablar de los "excesos" cometidos en el marco de la "guerra justa" contra la subversión. Este grupo proponía ofrecer a la sociedad algún tipo de registro de las personas "ausentes", presas o expulsadas del país, con el fin de morigerar las consecuencias en el futuro, de negar estos hechos. El otro sector, el de los "duros" o "halcones", por el contrario, deseaba seguir insistiendo públicamente con que había sido necesario para la sociedad argentina darle un escarmiento a la "subversión", la cual había desatado una violencia sin precedentes. Desde esta perspectiva se desestimaba toda preocupación por los riesgos políticos por venir a la hora de una transición a un régimen constitucional. ${ }^{15}$

Cuando Edmundo Vargas Carreño arribó en el mes de julio para acordar con la Junta el plan de actividades que cumplirán los miembros de la Comisión en su futura estancia en Buenos Aires, se logró precisar que se incluirían visitas a funcionarios oficiales del gobierno, dirigentes políticos, dirigentes de organismos de derechos humanos, entidades y personas representativas también de otros campos como el religioso, empresarial o estudiantil, y que también se reunirían con los presos y presas políticos. ${ }^{16}$

La CIDH planteó, además, no quedarse solo en Buenos Aires sino pedir entrevistas e indagar en otras zonas donde se había desarrollado una gran conflictividad social y política previa al golpe de marzo de $1976 .{ }^{17}$ Así, los miembros se repartirían entre ellos las visitas a las ciudades de Córdoba, Tucumán, La Plata, Trelew y Resistencia. Eso les permitía además, sumarle a la inspección de los penales metropolitanos de Villa Devoto y Caseros, los de Resistencia, Rawson, La Plata, Olmos y los centros militares de

15 Véase esta caracterización sobre como encarar la publicidad o no de la lucha antisubversiva en Canelo (2008, p.134).

16 "Llega hoy el secretario de la Comisión de Derechos Humanos", en Clarín, 22 de julio de 1979.

17 El gobierno militar debió enfrentar junto a la llegada de la CIDH, señales de la crisis económica y financiera que se avecinaba así como la multiplicación de una serie de conflictos gremiales. Para poder conmensurar este incremento a partir de 1980 ciertos análisis nos informan que los gremios llegaron a protagonizar "188 conflictos en todo el país, movilizando a alrededor de 1.800.000 trabajadores, tres veces más que en 1978". Novaro y Palermo (2003, p. 325).Ver también este tema en Pozzi (1988) y Falcón (1996). 
Magdalena y la Rivera en Córdoba. También se completaría con visitas a los sitios de la Superintendencia de Seguridad Federal, la Escuela de Mecánica de la Armada (ESMA) y la Comisaría no 9 de Buenos Aires, lugares denunciados como centros clandestinos de detención (CCD). ${ }^{18}$

Esta consideración y puesta en preaviso de la CIDH de tomar audiencia en las cárceles les permitió a los afectados/as, preparar sus intervenciones y relatos, así como juntar numerosas pruebas sobre los vejámenes practicados por el sistema penitenciario. De este modo se comenzaron a trazar nuevas alianzas políticas junto a un reacomodamiento de las fuerzas opositoras.

Las autoridades militares les insistieron a los miembros de la Comisión que no correspondía que abordaran la situación de los derechos humanos en la Argentina, sin tomar en cuenta la violencia política y social preexistente a la asunción de la Junta. Con este fin, el ministro del Interior, Albano Harguindeguy, le hizo entrega a la Comisión de un documento voluminoso en el que se exponían diversos "actos terroristas" que fueron los que determinaron que las fuerzas armadas "asumieran el poder político en la República Argentina junto con la resposabilidad de contener la disolución progresiva del Estado, el caos generalizado y la situación de extrema indiferencia social $[\ldots]^{\prime \prime} 19$

En el contexto internacional de la ideología de la Guerra Fría no era, como señalamos, descabellado suponer que la voz de los militares fuera la que terminase prevaleciendo, ya que incluso los peores dictadores habían sido presentados por el gobierno norteamericano como luchadores por la paz dispuestos a salvaguardar a Latinoamérica del comunismo. Sin embargo, como las condiciones políticas y culturales habían cambiado sustancialmente, las cosas ahora no serían tan fáciles.

\section{EL GOBIERNO MILITAR CAMBIA SU CARACTERIZACIÓN DE LA CIDH}

La CIDH llegó a la Argentina entonces como producto de un reacomodamiento de la política internacional. Es cierto que contribuyeron con el estímulo de la visita los cambios promovidos en política exterior por el presidente de los Estados Unidos, James Carter, quien restringió el

\footnotetext{
18 Los CCD fueron instalaciones secretas donde las fuerzas armadas ejecutaron el plan sistemático de desaparición de personas. En ellos se alojaba, se torturaba y se asesinaba a los y las detenidos. Se calcula que hubo unos 500 CCD a lo largo de toda la Argentina.

19 Citado en Informe sobre la situación de los derechos humanos en Argentina, aprobada por la Comisión Interamericana de los Derechos Humanos en el 49. ${ }^{\circ}$ período de sesiones, 11 de abril de 1980, p. 26.
} 
apoyo que sus predecesores le habían procurado abiertamente a las dictaduras de la región. ${ }^{20}$ Sin embargo, no es posible reducir o explicar todo por medio de este elemento.

Para fines de los años setenta, la ola internacional de radicalismo que se había expresado en eventos como el Cordobazo en Argentina, el Mayo Francés o la Primavera de Praga en Europa, entre otros, estaba llegando a su fin. A la par surgían nuevas tecnologías de información y comunicación que influyeron en la creación y el cambio de una opinión pública, cada vez más globalizada y sensible a las violaciones en materia de derechos humanos de los regímenes autoritarios. De este modo, la institucionalización de la problemática de los derechos humanos junto al activismo global del exilio latinoamericano en México, Europa y Estados Unidos, visibilizó ante el mundo entero, el accionar de las dictaduras del Cono Sur. ${ }^{21}$ Esto estimuló a que los focos de resistencia al régimen militar argentino, que hasta allí habían sido silenciados, lograran proyectarse a nivel internacional.

Frente a esta situación, ciertas acciones del gobierno comenzaron a dar clara cuenta de su preocupación ante la visita de la CIDH. Primero se puso en evidencia la pérdida de confianza en que la Comisión produjese una opinión favorable respecto de la "lucha antisubversiva". Se hizo necesario para enfrentar este diagnóstico, articular un frente de defensa interno que respondiese a los reparos de la opinión pública internacional y local.

Un hecho gravitante, que sucedió en agosto de 1979, a poco del arribo de la Comisión, pone en evidencia cómo se fueron reorganizando las fuerzas sociales en favor y en contra de la "guerra sucia". Este fue el allanamiento a las oficinas de la Liga Argentina por los Derechos del Hombre (LADH), de la Asamblea Permanente por los Derechos Humanos (APDH) y el Movimiento Ecuménico por los Derechos Humanos (MEDH), tras la orden del juez federal dr. Martín Anzoátegui. Este magistrado, con fuertes ligaduras ideológicas con el régimen militar, justificó las inspecciones como parte del ineludible esclarecimiento en torno a las declaraciones que formulara la madre de

\footnotetext{
20 De hecho, en febrero de 1977, el secretario de Estado, Cyrus Vance, anunció ante el Senado norteamericano una reducción de los créditos militares a modo de "sanción" por las violaciones a los derechos humanos que se estaban desarrollando en la Argentina. Sin embargo, tan solo un año más tarde, en septiembre de 1978, el Departamento de Estado Norteamericano, no evitó que el Eximbank (The Export-Import Bank of the United States, la agencia de créditos para exportaciones de los Estados Unidos), ofreciera un plan financiero al gobierno militar argentino para construir la central hidroeléctrica de Yaciretá en los saltos del Río Paraná, en la provincia de Corrientes en Argentina. Ver, para este tema: “Ni soberanía de la tortura ni tortura de la soberanía", en La Opinión, 1. e marzo de 1977.
}

21 Ver este tema en Green (2009). 
una joven desaparecida, la cual "habría sido obligada" por miembros de las organizaciones político-armadas a comparecer ante la justicia federal con el fin de distorsionar los hechos relacionados con la detención de su hija, comprometiendo el accionar del gobierno. El juez consideró esta secuencia como parte de un fraude procesal, y decidió verificar, por lo tanto, si hubo o no instigación al falso testimonio. ${ }^{22}$

El secuestro de materiales de estos organismos de derechos humanos, base documental, paradójicamente, de la futura investigación de la Comisión, generó una expeditiva respuesta por parte de algunos funcionarios de los Estados Unidos. Entre ellas, se destaca la declaración de James Reston, portavoz del Departamento de Estado Norteamericano, quien sostuvo que "el allanamiento evidenciaba que los derechos humanos en la Argentina estaban siendo fuertemente cuestionados". ${ }^{23}$ Harguindeguy, que tomó nota del reto, replicó también con celeridad tales afirmaciones, señalando que este fue un acto totalmente legítimo y propio de las facultades del Poder Judicial. Por lo que es:

inadmisible e insólito que un funcionario extranjero pueda haber insinuado la posibilidad de indicar al gobierno argentino cómo proceder en el caso. [...], lo que se incorpora a una campaña ya ostensible [...] en la que se han aliado los delincuentes terroristas exiliados, los extremistas de todos los orígenes y muchos compañeros de rutas, que no quieren admitir que la República Argentina se puso de pie, los combatió y derrotó, refirmando su derechos de seguir siendo libres. ${ }^{24}$

Si bien la Doctrina de la Seguridad Nacional había sido elaborada en el extranjero, los militares argentinos habían logrado presentarla como la esencia misma de la identidad nacional. Con todo, resultaba, para el año 1979, un instrumento ideológico útil que permitía cuestionar la intervención de los Estados Unidos, un país que había sido representado, sobre todo desde la segunda mitad del siglo XX, por la izquierda y el nacionalismo revolucionario o tercermundista, no sin razones, como de carácter imperialista. La posición norteamericana de erigirse en veedora de las violaciones a los derechos humanos llevó a que el régimen militar se apropiara en cierta medida de un discurso "antiimperialista" con el objetivo de rechazar la posición esgrimida por el país del norte. De hecho la

22 Ver "Secuestran material utilizado para desprestigiar al país. Allanan la Comisión Nacional de Derechos del Hombre", en Convicción, 11 de agosto de 1979.

23 "No comentó Washington la réplica de Harguindeguy", en La Prensa, 18 de agosto de 1979.

24 "Terminante rechazo a opiniones sobre allanamientos y la visita de la CIDH. El gobierno refutó enérgicamente declaraciones de un vocero del Departamento de Estado", en Convicción, 17 de agosto de 1979. 
radicalización de esta posición condujo a que en el año 1982, la Junta, con el general Leopoldo Galtieri a la cabeza, propiciara la guerra contra los británicos en su intento de recuperar las islas Malvinas del Atlántico Sur.

En el ámbito local, una vez que se clarificó que no se iba a contar con los favores de la Comisión, el régimen logró aglutinar, como ya señalamos, fuertes adhesiones de distintas fuerzas sociales. Un ejemplo significativo de la nueva mirada que se postuló sobre los Estados Unidos, la expresó el Centro de Estudios Carlos Pellegrini de la ciudad de La Plata. Este núcleo de profesionales ligado a las ciencias duras, emitió un fuerte cuestionamiento a las facultades de la CIDH por indagar sin límites a detenidos "subversivos", presos comunes o a distintas figuras políticas. En un comunicado afirmaron que esta intervención era una violación de la soberanía, cuestionando el perfil ideológico de la conducción norteamericana: "[...] la notoria decadencia de la clase gobernante norteamericana ha debilitado su omnímodo poderío, permitiendo el avance del comunismo en sus distintas manifestaciones [...]"..25 Asimismo, diversos núcleos de juristas argumentaron que ninguna inspección podía tener legitimidad, pues la Argentina no formaba parte de ninguno de los acuerdos de la Convención Americana de Derechos Humanos. Ciertos sectores de la Iglesia como, por ejemplo, el arzobispo de San Juan, monseñor Idelfonso Sansierra, declaró ante la prensa que la presencia de la CIDH tenía una intencionalidad política subrayando especialmente la cuestión del quebrantamiento de la soberanía:

Debería preocuparse por otros países donde se violan abiertamente los derechos humanos. Debemos defender nuestra soberanía y si la Comisión excediera sus funciones, el gobierno, haciendo uso de sus facultades soberanas, debería dar por terminada su misión. ${ }^{26}$

La Sociedad Argentina de Defensa de la Tradición, Familia y Propiedad acusó a la OEA, a través de un comunicado de prensa, por no pronunciarse concluyentemente contra la actuación del comunismo en la Argentina. Ademais, la flamante Liga Argentina de las Víctimas del Terrorismo entregó un documento a la Comisión con el objetivo de que esta se comprometiese a obrar para impedir las salidas del país de los "delincuentes terroristas". La Liga de Madres de Familia, la Liga contra el Cáncer y numerosos sectores del empresariado tales como la Unión

25 "Es criticada la visita de la Comisión de la OEA", en La Nación, 3 de septiembre de 1979.

26 Clarín, 8 de agosto de 1979. 
Industrial Argentina, la Sociedad Rural Argentina y la Cámara Argentina de Comercio fueron otras de las entidades a favor del gobierno militar. ${ }^{27}$ Una solicitada en el diario La Prensa, sustentada por una abrumadora cantidad de firmas, manifestó su objetivo de contrarrestar la campaña del "terrorismo internacional", a la par que planteó "abrirle los ojos" a la $\mathrm{CIDH}$, para que se ilustra sobre lo que de verdad había estado sucediendo en la Argentina. ${ }^{28}$

También un editorial del diario La Nación insistía con la idea de que la Comisión debía tener en cuenta que el Estado argentino había perdido el monopolio de la fuerza frente a los grupos subversivos, por lo que había sido más que necesaria la apremiante intervención institucional tres años atrás. Sin embargo, decían, ahora, que la "subversión" se consideraba militarmente terminada, "urge afirmar en todos los terrenos los aspectos de fondo constitutivos de un Estado de Derecho [...]", por lo que la visita contribuiría seguramente a cerrar la etapa anterior. ${ }^{29}$

Tamaña movilización de fuerzas dejaba en claro que el gobierno militar ya no confiaba en los norteamericanos ni mucho menos en que la $\mathrm{CIDH}$ elaborase un informe favorable. Por el contrario este abriría una serie de interrogantes en torno a la "lucha antisubversiva" o pondría directamente en duda la estabilidad futura del régimen. En cierta forma, si bien los militares podrían haber insistido con su discurso negador sobre lo sucedido, empezaba a quedarles claro, que la grieta se abría y que por ella se colarían todas las acciones políticas de resistencia de las víctimas del terrorismo de Estado.

\section{LA ACTIVIDAD DEL FRENTE OPOSITOR}

De este modo la movilización que provocó la visita de la CIDH en la sociedad argentina había cambiado las coordenadas de la relación entre lo oculto y lo ostensible. Ahora existía la posibilidad de que la visibilización de la represión ya no actuara como pura coacción intimidatoria para apuntalar al régimen, sino, por el contrario, prometía transformarse en una hendidura que cuestionara su legitimidad. De este modo, la posibilidad de que la visibilidad de la violencia estatal cambiara de rol aparecía en el hecho mismo de poner en evidencia al terrorismo de Estado como pregunta. En este contexto, en

27 La Nación, 20 de septiembre de 1979.

28 "En testimonio de la verdad", en La Prensa, 19 de septiembre de 1979.

29 "La visita que comienza", en La Nación, 6 de septiembre de 1979. 
el activismo de los organismos de derechos humanos, creyeron posible interpelar a la CIDH y valorar la visita en clave política, y vieron en cierto modo, la posibilidad de amplificar su resistencia.

Mientras los militares que habían confiado en la prédica anticomunista de los norteamericanos por décadas, ahora se colocaban a distancia de ellos, los organismos de derechos humanos, los militantes populares apresados/as y los sobrevivientes del terrorismo de Estado en el exilio, que se habían mantenido alejados del "imperialismo norteamericano", ahora encontraban en el discurso que la OEA sustentaba en torno a los derechos humanos la posibilidad de erosionar al régimen militar y junto con ello de liberarse de la violencia a la que estaban siendo sometidos.

La nueva caracterización y la utilización política de estos vínculos permitieron aglutinar también fuerzas sociales que fortalecieron a las organizaciones de derechos humanos, dando impulso a que los familiares que hasta allí no habían articulado denuncias por la desaparición, expulsión o el maltrato carcelario de sus seres queridos, comenzaran a hacerlo.

Cuatro entidades argentinas defensoras de los derechos humanos cuestionaron abiertamente las medidas anunciadas por el ministro Harguindeguy, tendientes a declarar muertas a las personas desaparecidas durante los episodios de violencia política de años anteriores. Mientras el gobierno intentaba generar un "blanqueo" público de cifras de desaparecidos/as, quitando la bruma y hablando de muertos, los organismos le disputaban el hecho de no conocer las circunstancias de los fallecimientos ni el paradero de los cuerpos desaparecidos. La APDH, la LADH, el MEDH y la Comisión de Familiares de Desaparecidos y de Presos Políticos hicieron "una presentación conjunta a la Comisión de Asesoramiento Legislativo $(\mathrm{CAL}),{ }^{30}$ señalando que la justicia sería mejor servida si se determinaba el paradero de los desaparecidos, en lugar de, simplemente, declararlos muertos" ${ }^{31}$

Un texto firmado por obispos, pastores, monseñores y rabinos, que fue difundido por la LADH y el Partido Comunista (PC) a los medios de comunicación masiva, exponía la confianza y la esperanza en la actividad de la Comisión, la cual podría estimular ciertos cambios en la política

30 La CAL estaba integrada por nueve oficiales superiores designados por las tres fuerzas que tenían por función ejercer un asesoramiento legislativo en favor del Poder Ejecutivo Nacional así como sancionar "leyes" nacionales.

31 "Arribará el jueves la CIDH. Sus miembros mantendrán contactos oficiales y visitarán a los detenidos", en Clarín, 3 de septiembre de 1979. 
gubernamental en rubros tales como el régimen carcelario o el esclarecimiento de la desaparición de personas.

[...] expresamos nuestra aspiración de que la CIDH encuentre, al llegar a nuestro país y en relación a cuanto constituye su objetivo específico [...]: 1) la libertad de los detenidos a disposición del PEN sobre los que no pesan cargos, y el sometimiento a sus jueces naturales de aquellos otros sospechados de delitos; 2) una efectiva adecuación de régimen carcelario a los principios establecidos por la Constitución Nacional; 3) un diálogo abierto y sincero entre el Gobierno y el pueblo argentino sobre la situación actual del problema originado por el secuestro y desaparición de personas. ${ }^{32}$

El PC y la LADH entregaron a la CIDH cuatro carpetas extensas con denuncias de diversas violaciones a los derechos humanos y presentaciones a la justicia realizadas por miembros afectados de sus organizaciones. ${ }^{33}$

El prestigioso diario de origen sajón Buenos Aires Herald, desde los comienzos del régimen militar, se mantuvo a distancia del mismo, apoyando a las madres de los desaparecidos y a otros grupos de familiares de víctimas del terrorismo estatal. Esta publicación ofrecía en sus páginas, información sobre secuestros y detenciones, bajo riesgo de ser clausurada. De hecho su director, Robert Cox, fue detenido primero y amenazado de muerte posteriormente, hasta que en 1979, poco después de la visita de la CIDH, decidió abandonar la Argentina. El Buenos Aires Herald transmitió su encendida defensa de la visita del organismo internacional, disputando sentidos con aquellas fuerzas sociales que argumentaban en favor del principio de territorialidad. Con esta perspectiva se señalaba:

La CIDH es uno de los organismos más respetados del hemisferio, y visita nuestro país por invitación del gobierno de las fuerzas armadas. Por lo tanto toda sugestión de que la Comisión está inmiscuyéndose es no sólo ofensiva para los distinguidos invitados sino que es una afrenta para el gobierno y las fuerzas armadas [...] El dictamen de la CIDH contribuirá a que el país comprenda exactamente cuánto pagó - en sangre, lágrimas y sufrimiento -, por la esperanza de hacer de la Argentina una democracia otra vez. ${ }^{34}$

32 Comisión Provincial por la Memoria, archivo DIPBA, Mesa DS, Carpeta Varios, Legajo 14.403. Asunto: Memorando estrictamente confidencial y secreto. Producido por DGIPBA, Señor Jefe Delegación Cap. Fed., para información del Señor Director General de Icia. de La Plata, 27 de agosto de 1979.

33 La Prensa, 9 de septiembre de 1979. Es importante destacar la participación del PC en esta nueva ola de defensa de los derechos humanos, ya que esta corriente política no había formado inicialmente parte del arco opositor a la dictadura. Por el contrario le había proporcionado apoyo al régimen militar, caracterizando a Jorge Rafael Videla y a Roberto Viola como el ala "blanda" del generalato.

34 "Prueba de la verdad", en Buenos Aires Herald, 7 de septiembre de 1979. 
El nuevo mapa político que se configuró con la institucionalización de la problemática de los derechos humanos en el marco nacional e internacional les puso ciertos límites, además, a las personas que hasta allí habían manifestado una actitud negadora. Escenificada esta conducta en la célebre frase "del por algo será que se los habrán llevado", a partir de la visibilización de este tema, la sociedad argentina comenzó a asumir una posición más activa acerca de lo sucedido en los años más represivos del régimen militar.

En general, entonces, la visita de la $\mathrm{CIDH}$ fue aprovechada como un modo de limitar la actividad represiva del Estado. Algunos dieron curso a intervenciones públicas, documentos, comunicados, declaraciones y reclamos en diarios masivos de listas de presos/as o desaparecidos/as. Otros se ocuparon de la recolección de información y de su correcta presentación en las instancias de amparo internacional. Se confeccionaron petitorios y se pegaron afiches en la vía pública. Se hicieron marchas y movilizaciones hacia distintas dependencias del gobierno. Hubo reuniones con numerosas personalidades y participación en eventos para que estos intercedieran en su favor, como fue, por ejemplo, el caso de la Conferencia Episcopal Argentina en abril de 1980. Los familiares presentaron pedidos individuales y colectivos de hábeas corpus. También se emitieron infinidad de cartas personales denunciando y pidiendo colaboración en el exterior. Los familiares, los presos y presas políticos y los organismos de derechos humanos se convirtieron en promotores y agentes de la visibilización de la problemática de la violación a los derechos humanos.

De conjunto, esta intensa actividad permitió construir múltiples redes solidarias entre familiares y organismos de derechos humanos, así como la consolidación de estos últimos y de sus demandas en el período de transición a la democracia. Todos los que participaron de este proceso tomaron el riesgo de exponerse públicamente y con ello de ser objeto de nuevos castigos. Si bien la represión para septiembre de 1979 había menguado en intensidad, las desapariciones, los secuestros y los encarcelamientos, sin embargo, seguían produciéndose.

\section{LA LLEGADA DE LA COMISIÓN Y LAS RECOMENDACIONES PRELIMINARES}

Cuando la Comisión llegó a Buenos Aires, estableció su sede de representante de la OEA en la calle 25 de Mayo 760, en pleno centro de la Capital Federal, a pocos metros de la Casa de Gobierno. La Comisión estuvo integrada por siete juristas de diferentes países de América, los 
cuales se propusieron dividir tareas y trabajar en subcomisiones. ${ }^{35}$ Esta se planteó recibir a todas las personas y entidades que quisiesen realizar denuncias en torno a violaciones a los derechos humanos.

Se reunieron con numerosos familiares de detenidos/as y de personas desaparecidas, así como con presos y presas políticos, respecto de los cuales, durante su estancia en la Argentina, nunca realizaron ninguna declaración, con el objetivo de preservar su integridad como testimoniantes.

Recibió por separado a los miembros que se hicieron presentes de la Asamblea Permanente de los Derechos Humanos, la Liga Argentina por los Derechos del Hombre, el Movimiento Ecuménico por los Derechos Humanos, las Madres de la Plaza de Mayo y la directiva del grupo Familiares de Desaparecidos y Detenidos por Razones Políticas. Todos estos grupos fueron los primeros que ofrecieron sus testimonios. Posteriormente se recibieron delegaciones de organismos en actividad en algunas ciudades del interior del país, que viajaron a Buenos Aires para ofrecer otras denuncias. Entre ellas se destacan: los Familiares de Desaparecidos de las Ciudades de Mendoza, Rosario y La Plata; la Sociedad de Abuelas de Niños Desaparecidos; Familiares de Menores de Edad Desaparecidos; Familiares de Periodistas Desaparecidos y Detenidos; Familiares de Conscriptos Desaparecidos; Familiares de Uruguayos y Chilenos Desaparecidos, y la Delegación de Jóvenes de la Asamblea Permanente por los Derechos Humanos.

La CIDH recogió un número de denuncias que ascendió a la espectacular cifra de 5.580. De este total fueron completamente nuevas 4.153 denuncias ya que 1.261 remitían a casos ya registrados, oficialmente en trámite y previamente recepcionados antes de la llegada de la Comisión. Un ejemplo de ello es la denuncia sobre apropiación de niños que por primera vez, en noviembre de 1977, las abuelas de Plaza de Mayo llevaron ante la CIDH. ${ }^{36}$

Ese nivel de visibilidad que adquirieron los familiares y los organismos en esta coyuntura, no les ahorró, ni a ellos ni a los integrantes de la Comisión, el desprecio de numerosos sectores. ${ }^{37}$ Inclusive mientras todo esto sucedía, se produjo la desaparición de una familia completa, en la zona de Munro, una localidad del

35 Estos eran: Edmundo Vargas Carreño, Andrés Aguilar, Luis Demetrio Tinoco Castro, Marco Gerardo Monroy Cabra, Carlos Dunshee de Abranches, Tom Farer y Francisco Bertrand Galindo, más personal técnico y administrativo.

36 Ver Resolución n. ${ }^{\circ}$ 31/78. Caso n. ${ }^{\circ}$ 2553. Argentina. CIDH, 18 de noviembre de 1978, en www.cidh.org.

37 "Hubo desprecio, gritos y provocaciones", en Página 12,15 de septiembre de 2009. 
Gran Buenos Aires, con el objetivo de amedrentar y poner en evidencia que la violencia estatal seguía activa y que las internas militares se resolvían con asesinatos y secuestros en las calles. De cinco miembros que tenía esta familia desaparecida, tres eran menores de edad, lo que agravaba la brutalidad del caso, ya que difícilmente se podría calificar a los niños de "delincuentes terroristas". El secuestro, que sería gravitante para el futuro informe de la Comisión, provocó una gran conmoción entre los miembros de la $\mathrm{CIDH}$, así como entre los organismos de derechos humanos. ${ }^{38}$ Vargas Carreño rápidamente informó su preocupación al gobierno, y la Comisión se puso en contacto inmediatamente con la Cancillería argentina para solicitarle las explicaciones correspondientes del caso, al jefe de la Policía Federal, por entonces, Juan Bautista Sasiaiñ. ${ }^{39}$

Sin solución de continuidad se instaló entre las fuerzas opositoras y las defensoras del gobierno un debate estimulado por estos hechos. A los pocos días, y aprovechando la gravedad de lo sucedido, se publicó una solicitada en el diario Clarín, con el título "Queremos la paz, pedimos justicia" por parte de los familiares de los obreros y empleados desaparecidos de la fábrica automotriz Mercedes Benz. En ella se pedía el esclarecimiento del paradero de los obreros desparecidos en el año 1976 y el castigo a los responsables. ${ }^{40}$

La misma policía que estaba siendo interpelada por la CIDH negó que hubiese grupos para policiales operando clandestinamente en la Argentina. Sasiaiñ informó, además, con el afán de quitarle potencia a las denuncias, que miembros de su fuerza habían encontrado a dos personas denunciadas como desaparecidas. ${ }^{41}$ Asimismo el juez Martín Anzoátegui sostuvo, públicamente, que de las listas de desaparecidos existentes, alrededor de cuatrocientas de esas personas viven en el exterior y otras cincuenta se encuentran detenidas en cárceles político-legales. ${ }^{42}$

38 El secuestro de la familia González fue denunciado por allegados a la misma ante la CIDH. Numerosos vecinos, además, dieron información acerca de cómo este había sucedido. Por ellos se supo que, de los cinco detenidos ilegalmente, solo la madre con los tres niños pequeños, fueron subidos encapuchados a un auto policial. Clarín, 17 de septiembre de 1979.

39 Crónica, 17 de septiembre de 1979.

40 Clarín, 20 de septiembre de 1979.

41 Clarín, 18 de septiembre de 1979.

42 Diario Popular, 18 de septiembre de 1979. 
Si anteriormente la violencia había sido instalada con cierta visibilidad, ya que su relativa exhibición ayudaba a atemorizar al conjunto social, ahora la constatación de esa violencia por un organismo fiscalizador, además de ratificar y dar crédito a las denuncias de los familiares y de los organismos de derechos humanos, se convertía en un recurso clave que iba contra la legitimidad del régimen.

Se entrevieron una serie de intercambios públicos, reacomodamiento de sectores, radicalización de posiciones, cartas abiertas y solicitadas. La llegada de la CIDH había condensado ciertas tensiones sociales y catalizado, además, las disputas. Como ya señalamos, la visita fue una oportunidad para que los familiares y organismos de derechos humanos reorganizaran el hilvanado de las denuncias y su fundamentación a través de la recolección de pruebas fidedignas. Los familiares y los organismos de derechos humanos comenzaron a constituir, de este modo, un relato propio que disputaba sentidos con el discurso oficial.

Con todo, la Comisión entregó el 20 de septiembre un sucinto informe. Estesellamó"Recomendacionespreliminares". Enestaslíneassedetallaban aquellosasuntosquerequerían una prontaatenciónyquenoaceptabanmás demoras en el tiempo. Los cambios que la CIDH sugirió fueron numerosos y producto de un diagnóstico negativo y obtenido luego de relevar dolorosos testimonios a familiares de personas desaparecida o presas. Este escrito fue el antecedente inmediato del informe de abril de 1980.

\section{EL POLÉMICO INFORME DE LA CIDH Y LA RESPUESTA DEL GOBIERNO}

Tras la partida del país del organismo internacional, el régimen comenzó entonces a pugnar por los resultados esgrimidos por la Comisión, lo cual siguió obligándolos a un debate público. El ministro del Interior, que fue uno de los más activos en esta querella, y quien manejó las relaciones con la Comisión, sostuvo que la Argentina se animó a mostrarle al mundo entero su combate contra el terrorismo internacional, por lo que "debe quedar claro que no nos hemos confesado ante la Comisión Interamericana de Derechos Humanos"43 ya que los argentinos solo lo hacen ante su Dios.

43 "No nos confesamos ante la CIDH, dijo Harguindeguy", en La Opinión, 22 de septiembre de 1979 . 
Para el mes de enero de 1980 ya circulaba una versión del informe. El Estado argentino tendría hasta el último día de febrero para entregar sus comentarios, realizar descargos y manifestar conclusiones, siendo el manuscrito estrictamente reservado. ${ }^{44}$

La difusión en Washington definitiva del informe de la CIDH estuvo prevista para el lunes 21 de abril de 1980.45 Sin embargo, el gobierno argentino convocó a una ronda de prensa para el día 19, dos días antes, en las oficinas de la Secretaría de Prensa y Difusión de la Casa de Gobierno. Allí se entregó solo una copia exclusivamente de las conclusiones del informe a los periodistas y se requirió que el domingo, 20, se reprodujera in extenso la respuesta ampliada del gobierno. ${ }^{46}$ La Junta dijo que rechazaba categóricamente el informe por ser poco ecuánime, con un tono general incriminatorio y con una metodología que ocultaba y distorsionaba la realidad. Días después, ante eventuales interpelaciones de distintos sectores antigubernamentales con motivo de haber proporcionado a los diarios solo las conclusiones del escrito de la Comisión, el gobierno se escudó, indicando que era innecesario dar a conocer todo lo que allí se decía, pues las conclusiones mostraban una síntesis sumamente calificada. En efecto el gobierno intentaba por todos los medios a su alcance encubrir las detalladas denuncias que la comunicación proporcionaba.

El informe de la CIDH se realizó tomando en consideración tanto la indagación realizada en la Argentina (denuncias, testimonios, observaciones in situ) como los documentos solicitados al gobierno. ${ }^{47}$

44 "Descargos oficiales por el informe que elaboró la CIDH", en La Prensa, 8 de enero de 1980. Un buen análisis sobre la polémica entre los informes ver en Jensen (2010, p. 151-173).

45 El canciller brigadier Carlos Washington Pastor expresó que el informe "no es lo justo, ecuánime y objetivo que debería haber sido", sintiéndose por lo tanto defraudado por una misión diplomática de envergadura como fue la de la CIDH. "Pastor dijo que el informe de la CIDH no es justo, ecuánime y objetivo", en Convicción, 6 de enero de 1980.

46 La respuesta del 20 de abril de 1980 fue incorporada al poco tiempo, y por resolución del ministro de Educación, Juan Llerena Amadeo, como texto para el programa de la asignatura Historia de la Currícula de tercer año de la escuela secundaria. Informe sobre la situación de los derechos humanos en Argentina (octubre de 1979 a octubre de 1980), Centro de Estudios Legales y Sociales (CELS, p. 46).

$47 \mathrm{La}$ CIDH declaró en su informe que ante cada denuncia formal que recibía de ciudadanos u organismos de derechos humanos, el gobierno tenía el derecho de presentar una apelación y observaciones en un plazo no mayor al de los 180 días. La respuesta a la vez debía retornar para su revisión a quien había formulado la denuncia, con el objetivo de que esta pudiese ser contestada. Luego la CIDH tomaba una decisión final sobre cada caso, puntualizando con argumentos específicos. 
Todos estos escritos se leyeron a la luz de la legislación existente antes del golpe de Estado y en comparación con la legislación vigente desde marzo de 1976. La jurisprudencia y las normas internacionales en materia de derechos humanos también fueron parte del marco de interpretación. El informe de más de trescientas páginas, muy documentado, colocaba en el centro del análisis la responsabilidad del Estado ante la generalización de detenciones arbitrarias, torturas, el asesinato de un número muy alto de ciudadanos y numerosísimas desapariciones. A la par ponía en evidencia las formas clandestinas del funcionamiento de tal accionar.

Si bien esto último era el nudo fundamental del documento, no se dejaban a un lado otras preocupaciones expresadas en las denuncias. En torno a la cuestión de los presos políticos se insistió por ejemplo con la cuestión del maltrato carcelario por medio del confinamiento en celdas de castigo, sujeción con cadenas, abusos en distintas partes del cuerpo durante las requisas, amenaza de violaciones, maltrato médico y subalimentación y deshidratación por un lado, así como los simulacros de fusilamiento $y$, a veces, el fusilamiento efectivo en presencia de otros prisioneros en el ámbito penitenciario, por otro. Numerosos fueron los testimonios que obtuvo la CIDH en distintas cárceles federales y provinciales de los presos y las presas políticos. ${ }^{48}$ Muchas de estas declaraciones ponen el acento en la arbitrariedad del Poder Ejecutivo durante el estado de sitio de detener por largos períodos de tiempo sin que medie proceso judicial alguno.

Entérminosgenerales, larespuestaquedioelgobiernoenel"contrainforme" tuvo por fin discutir un punto de vista políticosobre lo sucedido en la "lucha antisubversiva". En el prólogo al "contrainforme", el general de División y presidente del Círculo Militar, Carlos Augusto Caro, dejaba en claro que el gobierno, en su lucha contra la "subversión", lo que había hecho era ensalzar una "conciencia limpia de toda mácula". ${ }^{49}$ Esa misma conciencia es la que autorizó la presencia y actividad de la $\mathrm{CIDH}$, sin condicionamiento alguno en el propio territorio, para visitar, mirar, interrogar o preguntar lo que sea y a quien quisiese.

La estrategia militar fue tildar metodológicamente de poco rigurosa la confección del informe. Según esta perspectiva, sus técnicas consistieron

48 Informe sobre la situación de los derechos humanos en la Argentina, aprobada por la Comisión Interamericana de los Derechos Humanos en el 49. ${ }^{\circ}$ período de sesiones, 11 de abril de 1980, p. 217-9.

49 Observaciones y comentarios críticos del gobierno argentino al Informe de la CIDH sobre la situación de los derechos humanos en la Argentina, abril de 1980 (CíRCULO MILITAR, p. 6). 
en seleccionar un cierto número de denuncias y reproducirlas pródigamente. De este modo, sin evaluar lo relevante de lo que no lo es, el documento resultaba carente de requisitos de ecuanimidad y objetividad. Estos criterios, según el general Caro, estaban definidos de antemano, con conclusiones predeterminadas y con imputaciones que se encuentran en proceso de corroboración por la misma CIDH. Asimismo, en este escrito se objeta la falta de competencia de la Comisión para arrogarse cualquier función fiscalizadora, ya que no es un tribunal ni ninguna instancia judicial con prerrogativas para emitir fallos. ${ }^{50} \mathrm{El}$ objetivo del informe, según el gobierno, no era "investigar" sino enjuiciar la respuesta que el gobierno le dio a la "subversión":

En ningún caso se evidencia la menor desconfianza acerca de los pormenores que contiene cada una, por más sospechosos o inverosímiles que a veces puedan ser. Todo juicio crítico o negativo sobre la situación o sobre el gobierno es formulado en un tono asertivo que no admite controversia. ${ }^{51}$

Mientras en el informe de la CIDH se sostenía que habían disminuido las violaciones a ciertos derechos básicos y cesado las denuncias por desapariciones forzadas de personas, luego de la visita, el gobierno contra argumentaba, diciendo que era público y notorio que este proceso se venía cumplimentando desde por lo menos un año atrás, cuando las Fuerzas Armadas habían clausurado el período de "excepcionalidad". Una medida que además, tenía por propósito, también, blanquear la "lucha antisubversiva". Sin embargo continuaba el informe, en Europa o en México, los "subversivos" se habían reagrupado con el fin de organizar una campaña de descrédito del gobierno argentino, de la cual las autoridades de la CIDH se habrían hecho eco. ${ }^{52}$

Finalmente, lo más discutido y argumentado en el "contrainforme", por ser, a la vez, el punto crítico más importante respecto de la presión internacional, fue el tema de las desapariciones. Lo primero que se sostuvo es una discusión con respecto a las cifras. Mientras la CIDH creyó verosímil el número de 5.818 personas, el Ministerio del Interior solamente daba crédito a la existencia de 3.447 denuncias. Insistió, así, con que la CIDH había sobrevaluado todos los datos obtenidos. Asimismo,

50 Ídem, p.7.

51 Ídem, p. 9.

52 Ídem, p. 20. 
en su afán por desacreditar la información, dio un argumento para echar por tierra con el conjunto de la argumentación. Explicaba que en los enfrentamientos armados entre las fuerzas militares y las guerrilleras, hubo gran cantidad de muertos no identificados, siendo en numerosos casos producto de la vida clandestina de los "delincuentes terroristas", quienes no llevaban consigo identificaciones fidedignas. Por este motivo, al gobierno le resultaba imposible dar con las filiaciones verdaderas de las personas "caídas en combate". El documento militar agregaba además que era necesario tener en cuenta que otros militantes habían sido asesinados por sus propias organizaciones al revelarse actos de traición o deserción. Con estas puntualizaciones se pretendía afirmar que muchas de las personas que figuraban en las listas de desaparecidos vivían, sin embargo, cómodamente en Europa. Asimismo respecto de los detenidos políticos, este escrito sostuvo que la situación de estas personas, en virtud del estado de sitio, no sólo había mejorado desde un punto de vista reglamentario sino que se había reducido sustancialmente el número de personas en las cárceles. Si al 24 de marzo de 1976 había 2.662 detenidos, de esos, solo 1.428 permanecían detenidos a principios de 1980. Según este informe alrededor de 1.300 personas se encuentran bajo el régimen de libertad vigilada, otros cumplen arrestos domiciliarios y algunos han sido expulsados o han hecho uso del derecho de opción..$^{53}$

Como vemos, el gobierno militar creyó seriamente en la necesidad de rebatir los argumentos que la CIDH había publicado. Se vio obligado o quiso poner en discusión el valor y el reconocimiento por la "lucha antisubversiva". En buena medida, en la Argentina de fines de los años setenta, todos los actores sociales, a favor o en contra del régimen, comenzaban a intuir que el accionar del terrorismo de Estado se convertiría en el futuro cercano, en el "pasado que no pasa", haciendo peligrar la integridad de las Fuerzas Armadas.

\section{CONCLUSIONES}

Interpretamos que la llegada de la CIDH a la Argentina condensó una serie de cambios que estimularon la erosión del régimen militar en aspectos vinculados centralmente con la lógica represiva más cruenta y clandestina. La intervención de este organismo internacional provocó reagrupamientos y pronunciamientos en su favor y en contra.

53 Ídem, p.76. 
Mientras, los empresarios, la Iglesia católica, las asociaciones profesionales, las ligas de familia, entre otros, rechazaron la fiscalización de la Comisión, pues "violaba" los derechos de territorialidad de la Argentina; los organismos de derechos humanos, los familiares, presos políticos y exiliados en el exterior, vieron un estímulo a su accionar político, dinamizando sus actividades contra el Estado represor.

Las denuncias a la CIDH se constituyeron en un momento fundacional de las formas de organización del reclamo de los organismos, un largo camino que posteriormente se continuó con la actividad de la Comisión Nacional sobre la Desaparición de Personas (CONADEP), en los tribunales internacionales, y en toda la experticia que fue ampliamente desplegada con el fin de forzar cualquier resquicio de legalidad en favor de los diversos reclamos.

Si hasta allí había tenido una especial visibilidad solo el grupo de las Madres de Plaza de Mayo, la visita y la puesta en debate del accionar represivo le permitió al resto de los familiares, así como a otros organismos de derechos humanos, asumir una actividad cada vez más pública. Las diversas acciones llevadas a cabo se dieron, además, en un marco de colaboración y contribución que puso en evidencia que lo que afectaba a una familia afectaba a todas. De esta manera, la visita de la CIDH operó como un punto de inflexión. Lo invisibilizado ahora salía a la luz y aceleraba, además, las diferencias entre las distintas alas militares. Al mismo tiempo, tomaban cuerpo las acciones de los activistas de derechos humanos en escenarios cada vez más abiertos, y la opinión pública internacional rechazaba toda omnipotencia de las dictaduras del Cono Sur. Todos estos elementos fueron contribuyendo a la erosión y la pérdida de legitimidad del régimen militar. Aunque faltarían todavía varios años para la normalización institucional, la visibilidad de la violencia del Estado había dado a luz, al comienzo del fin.

Un aspecto significativo, ya no del pasado sino del presente, es que el Informe sobre la situación de los derechos humanos en Argentina elaborado por la CIDH en 1980, que contribuyó a modificar la ecuación entre lo oculto y lo visible en los años setenta, fue recientemente utilizado por los Tribunales Federales de la ciudad de Rosario en la provincia de Santa Fe, como una importante base documental para juzgar los delitos de lesa humanidad acaecidos en la región. 


\section{BIBLIOGRAFÍA}

BOUSQUET, J. P. Las locas de Plaza de Mayo. Buenos Aires: El Cid Editor, 1980.

CANELO, P. El proceso en su laberinto. La interna militar de Videla a Bignone. Buenos Aires: Prometeo, [s/d].

FALCÓN, R. La resistencia obrera a la dictadura. En: QUIROGA, H.; TCACH, C. (comps.). A veinte años del golpe. Con memoria democrática. Rosario: Homo Sapiens, 1996.

GARCÍA, A. La Doctrina de Seguridad Nacional. Buenos Aires: CEAL, 1991.

GARRETÓN, M. De la seguridad nacional a la nueva institucionalidad. Notas sobre la trayectoria ideológica del nuevo Estado autoritario. Revista Mexicana de Sociología, v. 40, n. 4, p. 1259-1282, 1978. DF: Universidad Nacional Autónoma de México, Stable URL: http://www.jstor.org/stable/3539657.

GREEN, J. Apesar de vocês: a oposição a ditadura militar nos Estados Unidos, 1964-1985, Companhia das Letras: São Paulo, 2009.

JENSEN, S. Los exiliados. La lucha por los derechos humanos durante la dictadura. Buenos Aires: Sudamericana, 2010.

LEAL BUITRAGO, F. La seguridad nacional a la deriva. Del Frente Nacional a la posguerra fría. Bogotá: Alfa Omega Editores, Universidad de los Andes, FLACSO-sede Ecuador, 2002.

NOVARO, M.; PALERMO, V. La dictadura militar 1976-1983. Del golpe de estado a la restauración democrática. Historia Argentina, n. 9, Buenos Aires: Paidós, 2003.

POZZI, P. La oposición obrera a la dictadura (1976-1982). Buenos Aires: Editorial Contrapunto, 1988.

ROBIN, M. Escuadrones de la muerte. La escuela francesa. Buenos Aires: Sudamericana, 2005.

SMITH, P. Talons of the Eagle: Latin America, the United States and the World. New York: Oxford University Press, 2008.

TAPIA VALDÉS, J. El terrorismo de estado. La Doctrina de Seguridad Nacional en el Cono Sur. México: Nueva Imagen, 1980.

La doctrina de la seguridad nacional y el rol político de las

fuerzas armadas. En: RUBINSTEIN, J. C. (comp.). El Estado periférico

latinoamericano. Buenos Aires: Eudeba, 1988.

\section{Diarios examinados}

Buenos Aires Herald

Clarín

Convicción

Crónica

Diario Popular

El Cronista Comercial 
La Nación

La Opinión

La Prensa

Página 12

\section{Documentos consultados}

Causa nº. 13/84 capítulo nº. XIX.

Comisión Provincial por la Memoria, archivo DIPBA, Mesa DS, Carpeta Varios, Legajo 14.413.

Comisión Provincial por la Memoria, archivo DIPBA, Mesa DS, Carpeta Varios, Legajo 14.403.

Informe sobre la situación de los derechos humanos en Argentina, CIDH, 1980.

Informe sobre la situación de los derechos humanos en Argentina, CELS, 19791980.

Observaciones y comentarios críticos del gobierno argentino al Informe de la CIDH sobre la situación de los Derechos Humanos en la Argentina, Círculo Militar, 1980.

\section{Páginas visitadas}

http://www.derechos.org/nizkor/arg/causa13/

http://foia.state.gov/SearchColls/Search.asp

Resolución n $n^{\circ}$.31/78. Caso n. 2553. Argentina. CIDH, 18 de noviembre de 1978, en http:// www.cidh.org. 